\title{
SOEP
}

SOEPpapers

SOEPpapers
on Multidisciplinary Panel Data Research

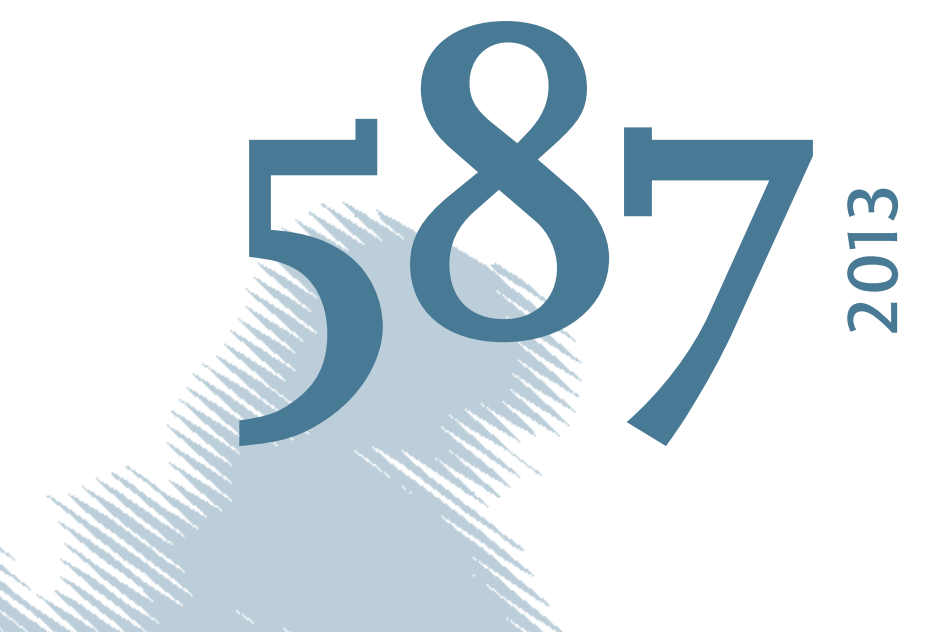

\section{Pooling and Sharing Income Within Households: A Satisfaction Approach}




\section{SOEPpapers on Multidisciplinary Panel Data Research}

at DIW Berlin

This series presents research findings based either directly on data from the German SocioEconomic Panel Study (SOEP) or using SOEP data as part of an internationally comparable data set (e.g. CNEF, ECHP, LIS, LWS, CHER/PACO). SOEP is a truly multidisciplinary household panel study covering a wide range of social and behavioral sciences: economics, sociology, psychology, survey methodology, econometrics and applied statistics, educational science, political science, public health, behavioral genetics, demography, geography, and sport science.

The decision to publish a submission in SOEPpapers is made by a board of editors chosen by the DIW Berlin to represent the wide range of disciplines covered by SOEP. There is no external referee process and papers are either accepted or rejected without revision. Papers appear in this series as works in progress and may also appear elsewhere. They often represent preliminary studies and are circulated to encourage discussion. Citation of such a paper should account for its provisional character. A revised version may be requested from the author directly.

Any opinions expressed in this series are those of the author(s) and not those of DIW Berlin. Research disseminated by DIW Berlin may include views on public policy issues, but the institute itself takes no institutional policy positions.

The SOEPpapers are available at

http://www.diw.de/soeppapers

\section{Editors:}

Jürgen Schupp (Sociology)

Gert G. Wagner (Social Sciences, Vice Dean DIW Graduate Center)

Conchita D'Ambrosio (Public Economics)

Denis Gerstorf (Psychology, DIW Research Director)

Elke Holst (Gender Studies, DIW Research Director)

Frauke Kreuter (Survey Methodology, DIW Research Professor)

Martin Kroh (Political Science and Survey Methodology)

Frieder R. Lang (Psychology, DIW Research Professor)

Henning Lohmann (Sociology, DIW Research Professor)

Jörg-Peter Schräpler (Survey Methodology, DIW Research Professor)

Thomas Siedler (Empirical Economics)

C. Katharina Spieß (Empirical Economics and Educational Science)

ISSN: 1864-6689 (online)

German Socio-Economic Panel Study (SOEP)

DIW Berlin

Mohrenstrasse 58

10117 Berlin, Germany

Contact: Uta Rahmann | soeppapers@diw.de 


\title{
Pooling and Sharing Income Within Households: A Satisfaction Approach
}

\author{
Susanne Elsas \\ University of Bamberg
}

\begin{abstract}
Standard household economics assumes that couples pool their incomes and share the sum equally, which is a necessary prerequisite for computing equivalent incomes and hence all statements about the distribution of personal incomes and income poverty. However, since cohabitation without marriage is on the rise and since income pooling is less frequent among cohabiting couples, income is also pooled and shared less frequently. In conclusion, statements based on these two assumption are becoming increasingly invalid.

Using data from the German Socio-Economic Panel Study, I analyze the incidence and determinants of income pooling and then proceed to determine whether couples who pool their incomes share the sum equally.

In contrast to most existing studies, I use a holistic approach to identify sharing within households by analyzing data on financial satisfaction. Concerning the relation between income sharing and income pooling, I account not only for the dominance of pooling over sharing, but also for the possibility of correlated error terms of the pooling and the sharing equation. A further advancement of this paper is the use of panel data, which enables me to account for unobserved heterogeneity at the household level.

The results indicate that the hypothesis of equal sharing even has to be rejected for couples who pool their incomes, which implies that a wide range of analyses of income poverty, for instance, may be misleading.
\end{abstract}

Keywords: income pooling, intra-household allocation, subjective well-being, twopart model

JEL Classification: D31, I32 


\section{Introduction}

Standard household economics assumes that couples pool their incomes and share the sum equally, which is a necessary prerequisite for computing equivalent incomes and hence all statements about the distribution of personal incomes and income poverty. As a consequence, inequality and poverty statistics may change substantially if these assumptions are violated (cf. Phipps and Burton, 1995). The increasing plurality of family structures raises doubts that the assumptions of pooling and equal sharing of incomes remain valid, because prior evidence suggests that the majority of cohabiting couples maintain systems of individualized management of resources instead of pooling each partner's whole income (Vogler, 2005; Kenney, 2006; Lyngstad et al., 2010). Implications based on assumptions of the pooling and equal sharing of incomes therefore remain valid for a declining number of households, if at all. If at least the potentially declining number of couples who pool their entire incomes also share the whole sum equally, then the validity of the equal sharing hypothesis is only restricted in its range. Conversely, if not even those who pool their incomes share them equally, then the hypothesis must be rejected.

In addition to the theoretical importance of pooling and sharing of income, financial relations between partners, or spouses, are important aspects of daily life. Vogler (2005, p. 3) describes how the ideal of "... a partnership between equals, based on love, sharing and equality, in which all resources are shared equally, regardless of who contributes what to the household..." conflicts with each individual's position in the labor market, where individuals earn their own money and "... are seen as having a legitimate right to both more say over how the money is used an more money for their own use... " (Vogler, 2005, p. 3). Accordingly, Papp et al. (2009, p. 91) show that "... marital conflicts about money were more pervasive, problematic, and recurrent, and remained unresolved, despite including more attempts at problem solving." For unmarried couples, Dew (2011) even finds that perceived unfairness in financial issues predicts union dissolution.

Before proceeding any further, it may be useful to clarify the concepts of income pooling and sharing, since economists and sociologists who are both involved in studying the intra-household allocation of money use the expression "income pooling" differently. Whereas the sociological interpretation refers to processes within the household, the economic notion refers to the final results of household behavior. 
To be more precise, among sociologists, income pooling describes the money management system of a couple, i.e. how partners deal with the fact that they each receive a potentially different income and both face shared expenditures, e.g. for rent, heating or the children (Pahl, 1989; Heimdal and Houseknecht, 2003; Vogler et al., 2006; Lyngstad et al., 2010; McRae, 1993; Winkler, 1997; Lewis, 2001). From this perspective, income pooling is the first but necessary step of allocating income, i.e. sharing income between household members. Partners can only share their income equally or unequally if they pool their incomes and both have access to the whole sum. Equal or unequal outcomes, such as consumption, would then be observed. This equality of outcomes corresponds to the economic notion of income pooling.

While the sociological notion of income pooling corresponds directly to processes within the household, the economic concept of income pooling offers a testable equal sharing hypothesis. It is derived from the unitary model of the household (Alderman et al., 1995) and relies on the marginal social utility of household income (Samuelson, 1956). The household is conceptualized to spend the family income such that the marginal utility of income is equal for each family member. If the marginal utility of the last unit of family income were higher if it was spent for, say, the husband, it would be spent on his behalf. If the allocation of family income within the household depends only on its marginal social utility, then distribution factors that do not shape preferences and prices should have no influence on the allocation of money within the household.

I follow this two-step notion about income pooling and sharing within households. The first step is the pooling of income: partners may pool all their incomes, they may pool part of their incomes or they may not pool any of their income. Assuming that income is pooled, the second step addresses whether partners share their income equally, whereby equal sharing is defined as the sharing of income leading to equal welfare levels between partners. Bonke (2013) also analyzes the duad of pooling and sharing and concludes that the woman's consumption share depends on her relative income contribution (i.e. her income share), even for couples who pool their incomes. In fact, Bonke (2013) fails to prove that an increased income share does not coincide with changes in preferences or needs, and hence changes in the consumption share. For example, the wife's need for business clothing may increase because she widens her labor supply, which also increases her income share. In this case, her consumption share is not a valid indicator of sharing between household partners because it is more likely to re- 
flect changes in needs (preferences) that are associated with changes in income share. In fact, equality between partners and spouses, and hence equal sharing, refers more to the well-being each partner gains from the household income than to consumption shares.

This paper contributes to the literature by using a more holistic strategy to identify equal sharing between household partners, i.e. it uses differences in partners' financial satisfaction. Additionally, I test whether pooling and sharing are determined by the same unobserved variables, which would require selectivity control when estimating the sharing equation. Finally, the panel quality of the data allows me to cancel out heterogeneity at the household level by estimating a fixed effects regression to test the equal sharing hypothesis.

The remainder of the paper is structured as follows: in the next section, I review previous findings on the pooling and sharing of income. In Section 3, I present my strategy to identify the equal sharing of income and the data I use. The results for the incidence and determinants of income pooling are presented together with the test of the equal sharing hypothesis in Section 4 . The conclusion summarizes and relates the findings to the initial questions.

\section{Previous Findings}

Two distinct disciplines gathered knowledge about the intra-household distribution of income, each with a different interest. Sociological research focuses on processes within households, which is why most information about income pooling stems from sociological research. Economic research, on the other hand, is concerned with the final outcome of the distribution process leading to the generation of knowledge about sharing between household partners.

\section{Income Pooling}

The seminal study for this question is that of Pahl (1989). She collected and analyzed data from British households in 1983, and developed a typology of money management systems, in which she distinguishes three types of income pooling from two privatized money management systems. The types of income pooling are (1) the female whole wage system, where the wife manages all the money except the husband's personal spending money, (2) the male whole wage system, where the wife receives a housekeeping allowance instead of personal spending money, 
and (3) a non-segregated joint pooling system, where the couple pools all the income, usually on a joint bank account. The two privatized systems are (1) that of partial pooling where the partners pool some of their income to pay for collective expenditures and keep the rest separate, and (2) the independent management system, where each individual manages his or her own income. She found that low-income households are more likely to practice the female whole wage system, whereas higher household incomes are usually managed by the husband. Vogler (2005) reports about a study conducted by Ludwig-Mayerhofer (2000) who found that about $70 \%$ of married couples in Germany use the non-segregated joint pooling system to manage their money, whereas cohabiting couples mainly manage their money separately. Similar patterns are found for Norway, Sweden and Canada (Vogler, 2005; Lyngstad et al., 2010). However, most cohabiting couples who have at least one biological child together pool incomes, similar to married couples (McRae, 1993; Winkler, 1997; Lewis, 2001). Couples who reported the entire pooling of their resources were explored in greater detail by Vogler and Pahl (1993). They found that in more than $50 \%$ of cases, only one partner actually decides on financial issues, although they all claimed to take financial decisions jointly. According to Vogler (2005), this finding supports the hypothesis of Singh (1997) that equality is redefined as jointness, masking traditional inequalities within households, while maintaining the ideal of a partnership between equals. The findings of Vogler and Pahl (1993) and the hypothesis of Singh (1997) are the starting point for the discussion about equal or unequal sharing between household partners who state that they pool their entire incomes and manage their money jointly.

\section{Sharing of Income}

If couples manage their money jointly, they may agree or disagree on how much of the income should be saved and how the rest should be spent. If a couple repeatedly reaches financial decisions that are in line with one partner's preferences but not with the other's, they may manage their money jointly, but they clearly do not share equally: the partner whose preferences shape decisions more frequently gains more from the pooled income. If the decisions (probably not each and every single decision but on average) equally satisfy the needs and desires of both partners, they share equally. 
Several authors put forward theories to explain the mechanics within households that lead to equal sharing between household members ${ }^{1}$. The important feature is that household members act as though they are satisfying a unitary household welfare function, which is why (Alderman et al., 1995) summarized all such explanations as unitary models. According to these models, each household member's desires are met by using the household income until the marginal utility of the last unit of money would be higher if it were spent on behalf of another member of the family/household. In other words, only changes of prices or preferences lead to changes in household decisions and their outcomes. This implies that the outcome of household decisions is independent from distribution factors (Alderman et al., 1995), i.e. factors that do not change prices and preferences of the household members.

Several tests of the unitary model yield rejections of the implied equal sharing assumption or, as economists call it, the income pooling assumption (Thomas, 1993; Bourguignon et al., 1993; Browning et al., 1994; Lundberg et al., 1997; Phipps and Burton, 1998; Kalugina et al., 2009; Bonke and Browning, 2009). Most of these studies use a diary of expenditures that usually covers only a short period of time to analyze spending on consumption of a number of assignable goods or for all assignable consumption. Indeed, the consumption of assignable goods is only one part of the welfare a partner gains from the household income. Even the decision on how much to save or the decision on which household items to buy, which cannot be assigned to any of the partners, may be in line with one partner's preferences and not the other's. One exception is the study conducted by Phipps and Woolley (2008), who analyze how distribution factors influence the amount each partner saves in a pension plan. Further, all these studies do not distinguish between households that pool incomes or manage money jointly and those that do not. Since the wife's income share is usually the main distribution factor (Bonke and Browning, 2009; Bourguignon et al., 1993; Browning et al., 1994; Kalugina et al., 2009; Lundberg et al., 1997; Phipps and Burton, 1998), the rejection of the equal sharing hypothesis may then also be driven by households that do not manage their money jointly. The only study that integrates the concept of income pooling in terms of the joint management of money and sharing of outcomes for household members, is that of Bonke (2013). He analyzes expenditure diaries that respondents kept for a period of two weeks, specifying for whom

\footnotetext{
${ }^{1}$ One of the first may have been Samuelson (1956); an overview is given by Bergstrom (1997).
} 
each item was purchased. The respondents further reported whether they pool all incomes and draw from this pool for both personal and collective purchases, whether they pool part of their incomes for collective costs and keep the rest for personal spending, whether they do not pool at all, or if one partner manages the money and gives the other partner some spending money or a housekeeping allowance. He tested whether the income share a women contributes to the household income predicts her share of expenditures, and compared the results of the income pooling subsample with the results for non-pooling households. He found weak evidence that the wife's income contribution is positively correlated with her expenditure share, even for income-pooling couples. His rejection of the equal sharing hypothesis is weak because it is restricted to couples where both partners work full-time. For couples where neither partner works full-time the wife's income share does not influence her expenditure share, i.e. the equal sharing hypothesis remains.

\section{Empirical Strategy}

Before presenting my strategy of analysis, I wish to summarize my arguments in order to reassess whether couples who pool their incomes share the sum equally, although Bonke (2013) found weak evidence against the equal sharing hypothesis.

Firstly, a test is performed to determine whether the rejection of the equal sharing hypothesis is independent of the empirical strategy used to identify sharing between household partners. The degree of inequality between household partners may be understated when sharing is identified through consumption, because the assignable goods are only one part of the partners' welfare. On the other hand, the degree of inequality may be overstated, since an increased expenditure share that coincides with an increased income share may be the result of changed preferences or needs, through enhanced labor market participation, for example. Using the couples' difference in financial satisfaction to identify welfare discrepancies I pursue a more holistic approach that seeks to overcome these shortcomings.

Secondly, I explicitly make use of the panel quality of the data, taking into account couples' specific heterogeneity, which may otherwise - if it remains uncontrolled - bias results. 
Thirdly, Bonke (2013) ignores the structural relation between the pooling and sharing of income, with a dominance of pooling over sharing, and the probably interrelated error terms of the pooling and the sharing equation. My empirical strategy explicitly takes this possibility into account.

Bonke (2013) concentrates his analysis on Denmark, and it is likely that the normative context and family and labor market policies shape within-household relations. Using a large German panel data set, I analyze the incidence and determinants of income pooling and sharing for Germany, which is a conservative welfare state compared to social-democratic Denmark (Esping-Andersen, 2011).

\section{The Sample}

This analysis uses data from the German Socio-Economic Panel (SOEP) ${ }^{2}$. The SOEP is a longitudinal survey of persons in households in the Federal Republic of Germany, run annually by the German Institute for Economic Research (DIW) in Berlin. It covers micro-data about demographic, economic, social and political topics, including a wide range of questions on subjective well-being.

The analysis is restricted to couples who live together, with and without children, who do not report conflicting marital status ${ }^{3}$, who answered all of the necessary items, and who gave corresponding information about their system of income pooling.

If one partner leaves the household and a new partner moves in, the new couple is no longer observed. The analysis is not restricted to couples in a certain age range as, for example, in Bonke (2013) or Kulic (2013). Such a restriction does not alter the preceding results substantially; estimates are available on request.

Since Frick et al. (2006) show that satisfaction data is unreliable in a respondent's first two years in the panel study, these observations are also dropped. I further excluded the top and bottom $1 \%$ of the distribution of satisfaction differences between partners, since Guven et al. (2012) showed that large satisfaction differences are predictors of divorce. Using the waves 2000 up to 2011, an unbal-

\footnotetext{
${ }^{2}$ The data used in this publication was made available by the German Socio-Economic Panel Study (SOEP) at the German Institute for Economic Research (DIW), Berlin. For details, see Wagner et al. (2007); Haisken-DeNew and Frick (2005).

${ }^{3}$ I dropped observations if one partner reports that they are married and live together with their spouse, while the other partner reports something else
} 
anced sample of $n=8749$ couples ( $\sum_{i=1}^{n} t_{i}=51736$ observations) is obtained for the estimations.

Descriptive statistics of relevant variables are presented in the Appendix in Table A.1

\section{Identification of Income Sharing}

Using a more holistic identification strategy, I seek to overcome the aforementioned shortcomings of assignable goods for examining income sharing. The theoretic interest is concerned with the distribution of the partners' welfare, where welfare means "the contribution to our well-being from those goods and services that we can buy with money" (Van Praag and Frijters, 1999, p. 427). Since this is not directly observable, we will compare the household partners' financial satisfaction as a vehicle for representing welfare.

When referring to an individual's welfare, it is necessary to assume that each individual is constantly able to transform the available income into welfare. Then, changes in welfare are driven by changes in income. Indeed, this conclusion requires extensive controls of the individual's circumstances, e.g. prices. If, instead, welfare discrepancies between household partners are used as an indicator of income sharing, many of the controls become dispensable because the circumstances of daily life of two individuals living together are fairly similar. Hence changes in welfare discrepancies between household partners will be driven by changes in the within household distribution of income.

However, welfare is not observed, whether observable at all. In the SOEP, however, respondents evaluate their financial satisfaction at the beginning of the questionnaire by answering the question: 'How satisfied are you today with the following areas of your life? Please answer by using the following scale: 0 means "totally unhappy", 10 means "totally happy". How satisfied are you with your household income?' Although the SOEP contains information about satisfaction with the respondent's personal income, this information is unsuitable for this analysis. In fact, $10 \%$ of women who do not have any income of their own did not answer this question, unlike women who have their own income. In regressions of satisfaction with personal income on household income and other regressors, the estimated effect of household income on satisfaction with personal income is more than twice as large if men have no income of their own compared to men with their own income (these results are available on request). This indicates 
that those who have an income of their own refer to their own income while those who do not have their own income refer to their share of the household income when answering the question about their satisfaction with their own income.

Research on financial satisfaction is well established (cf. Argyle, 1999; Ferrer-iCarbonell, 2013; Ferrer-i-Carbonell and Frijters, 2004; Diener et al., 1999; Stutzer, 2004; Van Praag and Frijters, 1999; Van Praag and Ferrer-i-Carbonell, 2004), and we know that financial satisfaction depends on several individual characteristics, such as age, education, gender, individual psychological attributes, labor market status (cf. Van Praag and Ferrer-i-Carbonell, 2004) and somehow on income. Schwarze (2003) shows that satisfaction with household income depends on equivalent income, rather than on total household income. Therefore, it is consistent to assume that financial satisfaction depends not so much on household income deflated by some fraction of the number of persons in the household (i.e. equivalent income), but on the welfare a person can draw out of his/her household's income, i.e. financial satisfaction depends on the welfare-effective income.

The connection between income and financial satisfaction has now been made, but the incomparability of welfare levels remains. It is impossible to know, whether different individuals use the same scale to translate welfare into financial satisfaction. However, if changes can be observed in the difference in financial satisfaction and if there are simultaneous changes in distribution factors, it can easily be concluded that the sharing of income depends on the distribution factor if everything else is controlled for. Satisfaction differences are also used by Elsas (2011) and Bonke and Browning (2009) to detect sharing within households; Kalugina et al. (2009) follow a similar approach, using the differences between partners' subjective evaluation of the household's economic situation (denoted the household's position on an economic ladder).

Since most partners differ with regard to attributes influencing satisfaction, unequal answers to questions concerning satisfaction do not necessarily express unequal welfare. For this reason, it is necessary to control for these attributes in order to examine the distribution of welfare between household partners, instead of relying merely on the distribution of satisfaction answers ${ }^{4}$. In this approach,

\footnotetext{
${ }^{4}$ Kalugina et al. (2009) choose a different approach to adjust self-reported financial satisfaction to deviances from experienced welfare: they compute an index with only three rough categories of satisfaction differences. They distinguish between (1) when the wife evaluates the household income as much lower than her husband, (2) when the husband and wife evaluate their household income more or less equally, with absolute differences of not more than one
} 
controlling for all other factors that may influence the evaluation process but not the individual's welfare-effective income or welfare is crucial. The derivation of the model is explained in detail in Elsas (2011).

The sharing equation therefore regresses satisfaction difference $\Delta s_{h t}$ between household partners at time $t$ not only on distribution factor $d_{h t}$, but additionally on each partner's attributes that are known to influence individual financial satisfaction, $x_{m h t}$ for the male partner and $x_{f h t}$ for the female partner. These are age, education, income and employment status (cf. Argyle, 1999; Van Praag and Ferrer-i-Carbonell, 2004).

Even household characteristics which are identical for household partners may influence the evaluation process for men and women differently; the term $x_{h t}^{\prime} \gamma$ controls for gender differences in the effects of some household characteristics.

$$
\Delta s_{h t}=\beta_{0}+x_{m h t}^{\prime} \beta_{m}-x_{f h t}^{\prime} \beta_{f}+x_{h t}^{\prime} \gamma+d_{h t}^{\prime} \delta+\eta_{h}+\varepsilon_{h t}
$$

Stochastic errors are kept in $\varepsilon_{h t}, \eta_{h}$ denotes the couple-specific error term, and the intercept contains the gender effect on financial satisfaction.

One major advantage of this analysis over similar work on this topic (Bonke and Browning, 2009; Kalugina et al., 2009) is the usage of panel data. In contrast, Bonke and Browning (2009) explicitly refrain from using within-household variation over time. Instead, they used only the first wave of their panel data set, asserting without further argumentation that they "find it unlikely that transitory changes in the distribution of within-household income would lead to significant contemporaneous changes of private expenditures" (Bonke and Browning, 2009, p. 35). I explicitly use the advantages of the data's panel quality to control for unobserved household heterogeneity, such as the particular constellation of individual psychological characteristics. It is well known that these stable individual characteristics have a major impact on responses to satisfaction items (Argyle, 1999; Diener et al., 1999). This means that an optimist and a pessimist will express diverging satisfaction regarding the same level of welfare, everything else held constant. Differences in self-reported satisfaction therefore depend on each couple's particular constellation of characters. In order to control for this heterogeneity, my econometric analysis of satisfaction differences relies only on

point on the nine-step evaluation scale, and (3) when the wife evaluates the household income as much higher (i.e. at least two points on the original evaluation scale). 
variation within each couple over time, as recommended for analyses of subjective well-being (Ferrer-i-Carbonell and Frijters, 2004). Such a fixed effects estimation can rule out couple-specific time-constant heterogeneity even if it is correlated to the explaining variables. It is very likely, for example, that couples differ in attitudes towards male and female roles in the household. These different attitudes may influence the partners' labor market participation and hence the distribution factor, i.e. the income share. The fixed effects estimation can therefore prevent the effect of the distribution factor from being overestimated.

On the other hand, it could be argued that satisfaction data is ordinal and hence requires the respective estimation methods, as used for example by Kalugina et al. (2009). But, in fact, whenever differences between partners' satisfaction scores are computed, a metric scale is implied. Taking the difference between 5 and 3 to equal the difference between 8 and 6 , equidistance between satisfaction scores is implicitly assumed, and then there is no need to refrain from estimation methods for metric data. This is even more the case because Ferrer-i-Carbonell and Frijters (2004) show that the consideration of fixed effects is more important for valid results than the limitation to estimation methods for ordinal data.

In order to test the equal sharing hypothesis, differences in financial satisfaction are to be explained (cf. Eq. (1)). To this end, the difference between the man's and the woman's reported satisfaction with the household income is computed, i.e. the husband's satisfaction surplus. This is positive when the man's financial satisfaction is higher than that of his partner; the difference is negative when the woman reports higher financial satisfaction.

This is no usual dependent variable but, as the spike plot (Fig. 1) shows, it is suitable for the estimation, since it is approximately normally distributed.

The generally small satisfaction difference between husband and wife is not surprising with regard to the findings of Van Praag and Ferrer-i-Carbonell (2004). The slight tendency towards the left end of the scale in Fig. 1 indicates slightly higher values of financial satisfaction for the wife.

The main explanatory variable is the distribution factor, the man's contribution to the household income. This is computed as the ratio of the man's income (gross monthly earnings as well as other individually assignable income, also in monthly gross amounts) to the sum of the man's and woman's income. Further controls for the sharing equation $\left(x_{m h t}\right.$ and $x_{f h t}$ in Eq. (1)) are: each partner's years in education, each partner's monthly gross income (including transfer income), in log values, each partner's weekly working hours, two dummy variables 


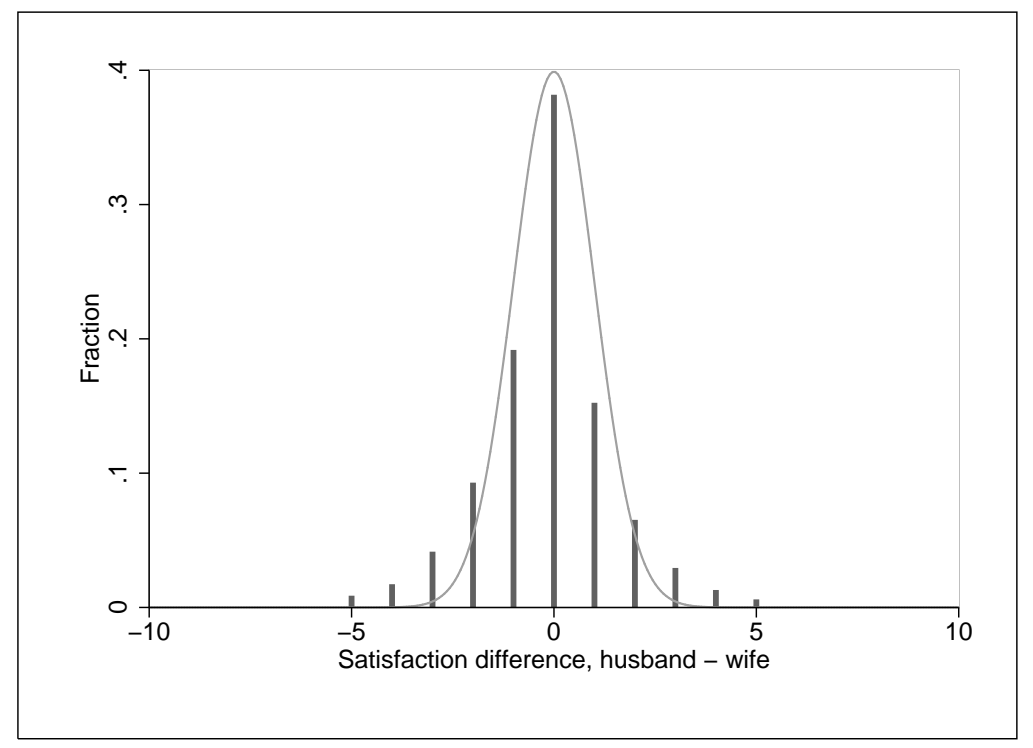

Figure 1: Husband's satisfaction surplus

indicating whether the man or the woman was unemployed at the time of the interview. These attributes are known to influence financial satisfaction (cf. Argyle, 1999; Ferrer-i-Carbonell, 2013; Van Praag and Ferrer-i-Carbonell, 2004). If partners differ in these attributes, differences in reported financial satisfaction are explainable by simple math. The satisfaction differences, which could stem from unequal sharing must exist after controlling for the partners' different endowment with satisfaction-influencing attributes. Further, household attributes that influence financial satisfaction are included as controls because they may influence women's and men's financial satisfaction differently. These are the household's income ${ }^{5}$ and $\operatorname{size}^{6}$, if children live in the household, the duration of the marriage (zero for unmarried couples), the legal status of the partnership (married or not), and the employment situation of the household (one binary variable indicating whether both spouses have the same employment level (full-time, part-time or not working), another indicating whether the partners' attachment to the labor market follows the male breadwinner scheme).

\footnotetext{
${ }^{5}$ Household income is not only the sum of both partners' incomes, but may even be more because some transfer incomes, such as taxes, child allowance and prolonged unemployment benefit refer to the household rather than to one of the partners.

${ }^{6}$ Household income and the number of persons in the household are included in log values, since Schwarze (2003) suggests using this flexible formulation instead of assuming an arbitrary deflation of the household income to compute an equivalent income.
} 


\section{The Interrelation of Pooling and Sharing}

Satisfaction differences are observable for all couples in the sample. However, these differences only contain information about income sharing for those who pool their incomes If couples do not pool their incomes, they only share the costs of living together, for accommodation, food and the children. For those couples, welfare comes from each partner's individual income, hence the satisfaction difference reflects differences in the partners' individual incomes and not the sharing between household partners. Eq. (2) shows the dominance relation of income pooling over income sharing.

In order to test the equal sharing hypothesis, the estimation of the sharing equation therefore needs to be restricted to couples who pool their incomes. This setting suggests a double-hurdle model (Jones, 1989), where the pooling decision dominates the sharing decision, i.e. a two-part model (Jones, 2000; Madden, 2008) or a subsample estimation with sample selection correction (Heckman, 1976).

$$
\Delta s_{h t}= \begin{cases}\beta_{0}+x_{m h t}^{\prime} \beta_{m}-x_{f h t}^{\prime} \beta_{f}+x_{h t}^{\prime} \gamma+i s_{h t}^{\prime} \lambda+\eta_{h}+\varepsilon_{h t} & \text { if } p_{0 o l} l_{h t}=1 \\ \beta_{0}+x_{m h t}^{\prime} \beta_{m}-x_{f h t}^{\prime} \beta_{f}+x_{h t}^{\prime} \gamma+\left(y_{m h t} / y_{f h t}\right)^{\prime} \zeta+\nu_{h t} & \text { if } p_{o o l}=0\end{cases}
$$

with

$$
i s_{h t}=f\left(d_{h t}\right)
$$

and

$$
\operatorname{pool}_{h t}=z_{h t}^{\prime} \alpha+v_{h t}
$$

Thereby $i s_{h t}=$ denotes income sharing as a function of the distribution factor $d_{h t}, y_{m h t}$ and $y_{f h t}$ are the husband's and wife's own income and $p_{0 o l} l_{h t}=1$ if the couple pools all incomes and the partners equally access the sum. Indeed, $i s_{h t}$ cannot be observed, but if couples pool their income and the distribution factor (i.e. the man's income relative to the woman's income) has a significant influence on the satisfaction difference between partners, this shows that the couple does not share independently of each partner's contribution to the household income. For the subsample of couples who do not pool their incomes, the distribution factor also influences satisfaction differences, but rather by comparison between the partners than through sharing household income. 
Whether a two-part model is appropriate or a sample selection correction is necessary depends on the correlation between error terms $v_{h t}$ and $\varepsilon_{h t}$ of the pooling and the sharing equation, Eqs (4) and (2). If errors of the pooling equation and sharing equation are uncorrelated, a two-part model is suggested (Madden, 2008); if errors are correlated, a selection correction is necessary. This is tested with the inverse mills ratio (IMR) from the pooling equation, Eq. (4). If in the sharing equation, Eq. (1), the IMR has a significant influence, the errors of the sharing and the pooling equation are correlated and hence a sample selection control is required.

\section{Identification of Income Pooling}

It is essentially not very difficult to identify couples who pool their incomes, since a question pertaining to this matter is included in the questionnaire. In the years 2004, 2005, 2008 and 2010, respondents are asked:

'How do you and your partner (or spouse) decide what to do with the income that either you or they or both of you receive?

1. Everyone looks after their own money

2. I look after the money and provide my partner with a share of it

3. My partner looks after the money and provides me with a share of it

4. We put the money together and both of us take what we need

5. We put a share of the money in together, and both of us keep a share of it for ourselves.

Bringing the partners' answers together, I obtain four possible categories of income pooling: (1) couples who do not pool their incomes at all, (2) couples who pool their incomes, but only one partner looks after the money and gives some to the other, (3) couples who pool their entire incomes and have equal access to the sum, and (4) couples who pool part of their incomes.

I restrict the estimation of Eq. (1) to couples of the third category: couples who pool all of their incomes and have equal access to the sum. It could be argued that the subsample of pooling couples should also contain couples who pool their incomes, but do not manage the pool jointly because it is in fact possible that they share their pooled income equally. However, if the equal sharing hypothesis was rejected using a subsample of couples with and without equal access to the 
pooled income, it could be suspected that the rejection is based only on those couples who do not have equal access to the pooled income.

Since information on income pooling is available in only four out of eleven years, and since Eq. (1) needs to be estimated using only the within variation, I predicted the probability of income pooling using a random effects probit model (cf. Eq. (5)). The out-of-sample prediction is necessary because the maximum of four (and moreover the mean of 2.4) observations per couple is not enough for a robust fixed effects estimation, since it requires calculating one parameter for each couple, which would hence rely on not more than four observations ${ }^{7}$.

The couples' pooling system is estimated on a subsample of $n=6758$ couples ( $\sum_{i=1}^{n} t_{i}=16018$ observations) according to the following equation.

$$
\operatorname{Prob}\left(\operatorname{pool}_{h t}=1\right)=\Phi\left(z_{h t}^{\prime} \alpha+\tau_{h}+v_{h t}\right)
$$

where:

pool $_{h t}= \begin{cases}1 & \text { if partners pool their entire incomes and have equal access to the pool, } \\ 0 & \text { if not. }\end{cases}$ $\Phi=$ cumulative density function of the normal distribution

$z_{h t}=$ vector containing the aforementioned household characteristics (as well as each partner's characteristics)

$\tau_{h}=$ household-specific error term, where $E\left(\tau_{h}\right)=0$ and $E\left(\tau_{h} z_{h t}\right)=0$

$v_{h t}=$ ideosyncratic error term

The explanatory variables for the pooling equation are the following household characteristics: whether the partners report equal employment level, whether they practice the male breadwinner model, whether they live in a rural or urban area, whether they live in their own property, whether children live in the household, whether both partners are immigrants, whether only one of them immigrated, the log of the equivalent household income (deflated by the square root rule), the income difference between partners, and the duration of their marriage, if they are married. Further, individual attributes are used to predict income

\footnotetext{
${ }^{7}$ Instead of a prediction based on the pooling equation, it would have been possible to take all married couples as if they pooled their incomes and all unmarried couples as if they did not pool their incomes, as performed by Kulic (2013), for example. I decided against this very rough distinction, because it is known from the literature review that cohabiting couples with children often pool their incomes, just like married couples.
} 
pooling, namely age, years in education, weekly working hours, age at marriage, whether they had been married before, and whether the respondent's mother was employed at the respondent's age of 15 , for each partner. Since separate estimations for married and unmarried couples showed that several explanatory variables are associated differently with income pooling for married and unmarried couples, interaction effects for all explanatory variables are included in the estimation equation.

For all years where there is no information about income pooling, I take predictions from Eq. (5) to complete the subsample I use later in order to test the equal sharing hypothesis. I also use this model to compute the IMR, which is necessary to test whether the sample selection correction is necessary.

\section{Estimation and Results}

The estimation requires two parts: the probit estimation of the pooling equation and the linear fixed effects estimation of the sharing equation.

\section{Determinants of Income Pooling}

The estimated coefficients for the pooling equation are presented in Table 1.

The estimates in the first column of Table 1 show that influences on income pooling differ for married and unmarried couples. The woman's education influences the probability of income pooling positively for married couples and negatively for unmarried couples. The same is true for the man's education in unmarried couples: the higher his education, the lower the probability of income pooling. The man's working time negatively influences the probability of sharing for unmarried couples, while the probability of income pooling is lower for married couples, the more hours the woman works. Couples where both partners lived in the German Democratic Republic (GDR) in 1989 are more likely to pool their incomes, whether or not they are married. The fact that marriage has no influence on the probability of income pooling for East German couples is in line with the high rate of children born to unmarried couples, since it is already known that unmarried couples with children are very likely to pool their incomes. Living in a rural area has directly opposed effects on the probability of income pooling for married and unmarried couples. Married couples who live in rural areas are less likely to pool their incomes, while unmarried couples in rural areas are more 
Table 1: Estimates for the pooling equation

\begin{tabular}{|c|c|c|c|c|}
\hline Variable & Coef. & S.E. & Coef. & S.E. \\
\hline Equal employment level & -0.085 & $(0.064)$ & $-0.108^{*}$ & $(0.060)$ \\
\hline Male breadwinner household & -0.111 & $(0.084)$ & -0.099 & $(0.081)$ \\
\hline Mother not working (m) & 0.134 & $(0.093)$ & 0.131 & $(0.089)$ \\
\hline Mother not working (w) & 0.125 & $(0.096)$ & 0.102 & $(0.092)$ \\
\hline Years in education $(\mathrm{m})$ & 0.015 & $(0.016)$ & 0.007 & $(0.016)$ \\
\hline Years in education (w) & $0.039^{* *}$ & $(0.018)$ & 0.026 & $(0.017)$ \\
\hline Working hours (m) & 0.003 & $(0.002)$ & 0.001 & $(0.002)$ \\
\hline Working hours (w) & $-0.004^{*}$ & $(0.002)$ & $-0.004^{* *}$ & $(0.002)$ \\
\hline Men married before & 0.007 & $(0.022)$ & 0.001 & $(0.012)$ \\
\hline Women married before & 0.010 & $(0.018)$ & 0.003 & $(0.012)$ \\
\hline Age $(\mathrm{m})$ & 0.063 & $(0.144)$ & 0.062 & $(0.142)$ \\
\hline Age (w) & 0.093 & $(0.149)$ & 0.054 & $(0.147)$ \\
\hline No children in the household & -0.106 & $(0.079)$ & $-0.187^{* *}$ & $(0.075)$ \\
\hline Immigrants & -0.088 & $(0.127)$ & -0.116 & $(0.125)$ \\
\hline One partner immigrated & -0.096 & $(0.176)$ & 0.000 & $(0.171)$ \\
\hline Both lived in GDR in 1989 & $0.243^{* * *}$ & $(0.092)$ & $0.291^{* * *}$ & $(0.087)$ \\
\hline Income difference & 0.017 & $(0.030)$ & 0.034 & $(0.028)$ \\
\hline Equivalent household income & -0.122 & $(0.085)$ & $-0.150^{*}$ & $(0.082)$ \\
\hline Living in rural area & $-0.245^{* * *}$ & $(0.066)$ & $-0.218^{* * *}$ & $(0.063)$ \\
\hline Living in owned flat & 0.004 & $(0.047)$ & 0.003 & $(0.046)$ \\
\hline Duration of the marriage & -0.005 & $(0.026)$ & 0.009 & $(0.007)$ \\
\hline Men's age at marriage & $-0.034^{*}$ & $(0.020)$ & $-0.027^{* *}$ & $(0.011)$ \\
\hline Women's age at marriage & $-0.029^{*}$ & $(0.016)$ & $-0.020^{*}$ & $(0.011)$ \\
\hline Unmarried couple & 0.827 & $(1.890)$ & $-3.551^{* * *}$ & $(0.369)$ \\
\hline \multicolumn{5}{|c|}{ Interaction effects for unmarried couples } \\
\hline Equal employment level & -0.048 & $(0.197)$ & . & . \\
\hline Male breadwinner household & 0.341 & $(0.328)$ & . & . \\
\hline Mother not working $(\mathrm{m})$ & -0.182 & $(0.300)$ & . & . \\
\hline Mother not working (w) & -0.437 & $(0.334)$ & . & . \\
\hline Years in education $(\mathrm{m})$ & $-0.117^{* *}$ & $(0.054)$ & . & . \\
\hline Years in education (w) & $-0.142^{* * *}$ & $(0.055)$ & . & . \\
\hline Working hours (m) & $-0.009^{*}$ & $(0.006)$ & . & . \\
\hline Working hours (w) & 0.000 & $(0.006)$ & . & . \\
\hline Men married before & 0.003 & $(0.029)$ & . & . \\
\hline Women married before & -0.015 & $(0.026)$ & . & . \\
\hline Age (m) & 1.515 & $(1.225)$ & . & . \\
\hline Age (w) & $-2.410^{* *}$ & $(1.183)$ & . & . \\
\hline No children in the household & $-0.575^{* *}$ & $(0.236)$ & . & . \\
\hline Immigrants & 1.513 & $(0.958)$ & . & . \\
\hline One partner immigrated & -0.642 & $(1.029)$ & . & . \\
\hline Both lived in GDR in 1989 & 0.242 & $(0.255)$ & . & . \\
\hline Income difference & 0.128 & $(0.085)$ & . & . \\
\hline Equivalent household income & -0.252 & $(0.302)$ & . & . \\
\hline Living in rural area & $0.396^{*}$ & $(0.220)$ & . & . \\
\hline Living in owned flat & -0.087 & $(0.199)$ & . & . \\
\hline Constant & $2.682^{* * *}$ & $(0.571)$ & $3.001^{* * *}$ & $(0.551)$ \\
\hline$\sum_{i=1}^{n} t_{i}$ & 16018 & & 16018 & \\
\hline $\mathrm{n}$ & 6758 & & 6758 & \\
\hline
\end{tabular}

Source: SOEP 2000 to 2011. Random effects probit estimation. 
likely to pool theirs. Previously married women who now cohabitate with a new partner are less likely to pool incomes with their partner, while this was not found for remarried women. When unmarried couples live together without children in the household they are less likely to pool their incomes, which corresponds to the findings of McRae (1993); Winkler (1997); Lewis (2001). The large number of interaction effects absorbs the effect of being married on the probability of income pooling, meaning that the main effect of being married disappears in the estimation when all interaction effects are taken into account.

\section{Prediction of Income Pooling}

More important than the effects of covariates are the predictions generated from the preceding estimations. Firstly, the estimates are used to determine the subsample of couples who pool or probably pool their incomes. The model does not predict behavior very well; the correlation between the legal status of the partnership and income pooling is much stronger for the predicted values than for observed behavior. One quarter of married couples who live together and two thirds of unmarried couples reported that they do not pool all of their income. Indeed, for years without the respective information, income pooling is predicted for $99 \%$ of married couples and for $9 \%$ of unmarried couples.

For the following estimations of the sharing equation (cf. Eq. (1)), reported information about income pooling is augmented by predictions for the years for which no reports on income pooling are available ${ }^{8}$. This implies that the sample selection is not perfect; it could be expected that some $14 \%$ of the couples in the selected sample do not actually pool their incomes.

Secondly, the estimates of the pooling equation are used to compute the inverse mills ratio (IMR) for couples who pool and probably pool their incomes. The IMR is included in the estimation of the sharing equation in order to control for potentially correlated error terms of the pooling and the sharing equation. An insignificant IMR indicates that the error terms are uncorrelated, but it may also be caused by multicollinearity between the IMR and the explanatory variables of the sharing equation. Since the IMR is in fact insignificant in the estimation of the sharing equation, the IMR is inspected in further detail. Leung and $\mathrm{Yu}$

\footnotetext{
${ }^{8}$ Since the estimated model does not explain much of the variation in income pooling, the sharing equation will be estimated from the subsample of couples who directly report income pooling in order to prove the estimates from the augmented subsample.
} 
(2000) argue that collinearity problems, and hence a bad selection control, arise if the IMR is linear in its argument for most of the observations in the pooling subsample, and the predicted values of the pooling equation are collinear with the covariates in the sharing equation. Jones (2007) further argues that a high proportion of unexplained variance in the selection (i.e. the pooling) model may also cause collinearity problems in the sharing equation and, in fact, the pooling model does not explain much of the variation in the couples' behavior.

The graphical inspection of the IMR in the pooling subsample, plotted against its argument, i.e. the predicted values of the pooling equation, shows that it is in fact linear for most of the range of its argument. However, compared to the cumulative distribution function it becomes apparent that most of the observations fall in the nonlinear range of the IMR. In fact, the linear prediction of the pooling model is above zero for $99 \%$ of observations, therefore in the nonlinear range of the IMR (cf. Figure 2). For a further inspection of the IMR, (Jones, 2007) suggests regressing it on the explanatory variables of the outcome equation, which yields an $R^{2}$ of 0.61 . This figure clearly indicates a certain amount of collinearity but is far from perfect collinearity.

In sum, estimates of the sharing equation are not expected to be blurred by multicollinearity.

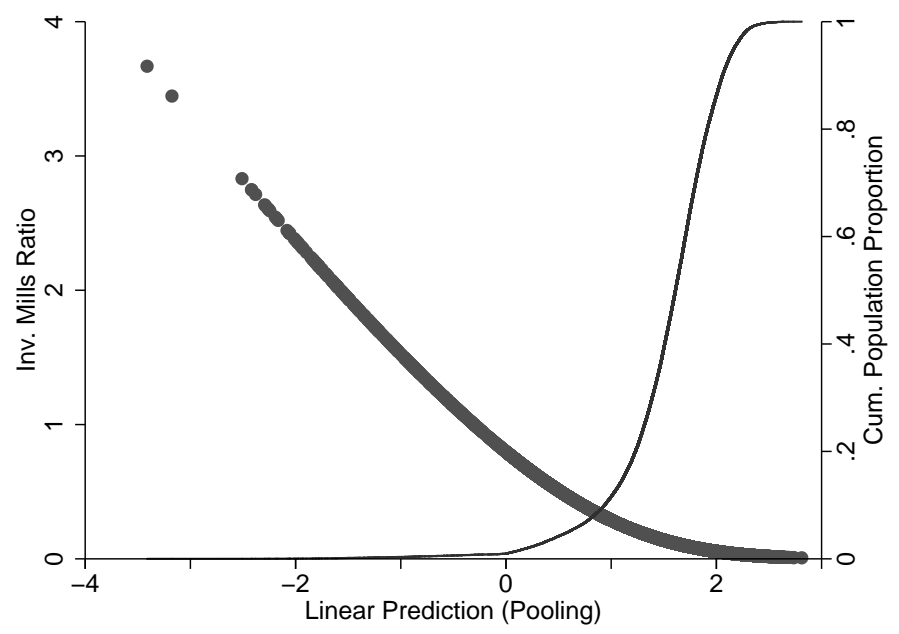

Figure 2: Inverse mills ratio 


\section{Determinants of Income Sharing}

The aim of this paper is to analyze whether couples who pool their incomes also share the sum equally. To this end, I estimate the sharing equation for the subsample of couples who pool and probably pool their incomes. When unobserved and therefore uncontrolled factors influence the pooling as well as the sharing of income, a simple subsample estimation will yield biased estimates. This can be tested by applying a straightforward t-test for the IMR in a subsample estimation of the sharing equation (Wooldridge, 2002, p. 116). The result is presented in the first column of Table 2. Since the estimated coefficient is very small and statistically insignificant, it is unnecessary to take the sample selection into account any further (Wooldridge, 2009, p. 610), which would require some adjustment of standard errors for all estimates. Estimates of the sharing equation for the augmented subsample of couples who pool their incomes are presented in the next column of Table 2. The estimates show that the distribution factor, the man's income share, predicts satisfaction differences, meaning that the hypothesis of equal sharing must even be rejected even for couples who pool incomes.

It is easy to interpret the effect of the distribution factor, because satisfaction differences are constructed as the husband's minus the wife's satisfaction, i.e. it is the husband's satisfaction advantage. This advantage is not always positive; for example when the wife's financial satisfaction exceeds that of her husband, the advantage is negative. I do not control whether the advantage really is an advantage or rather a disadvantage, since this is not necessary for rejecting the equal sharing hypothesis. Since the effect of the distribution factor is positive, the husband's satisfaction advantage (which is positive when the man's satisfaction exceeds that of the woman and negative when the woman's satisfaction exceeds that of the man) increases with his relative contribution to the household income. The positive effect of the distribution factor shows that the partner who brings in more income also gets more out of it. It is impossible to know exactly what happens behind closed doors - whether the partner who contributes more to the pooled household income also takes more out of it, or if the partner who contributes less to the household income hesitates to tap into the pooled income. Either way, these details are unnecessary for rejecting the equal sharing hypothesis and for getting a glimpse of the notion of justice between household partners. The significant effect of the distribution factor enables it to infer that, despite income pooling, the rights to decide on spending remain with income contribution. 
Table 2: Determinants of differences in financial satisfaction

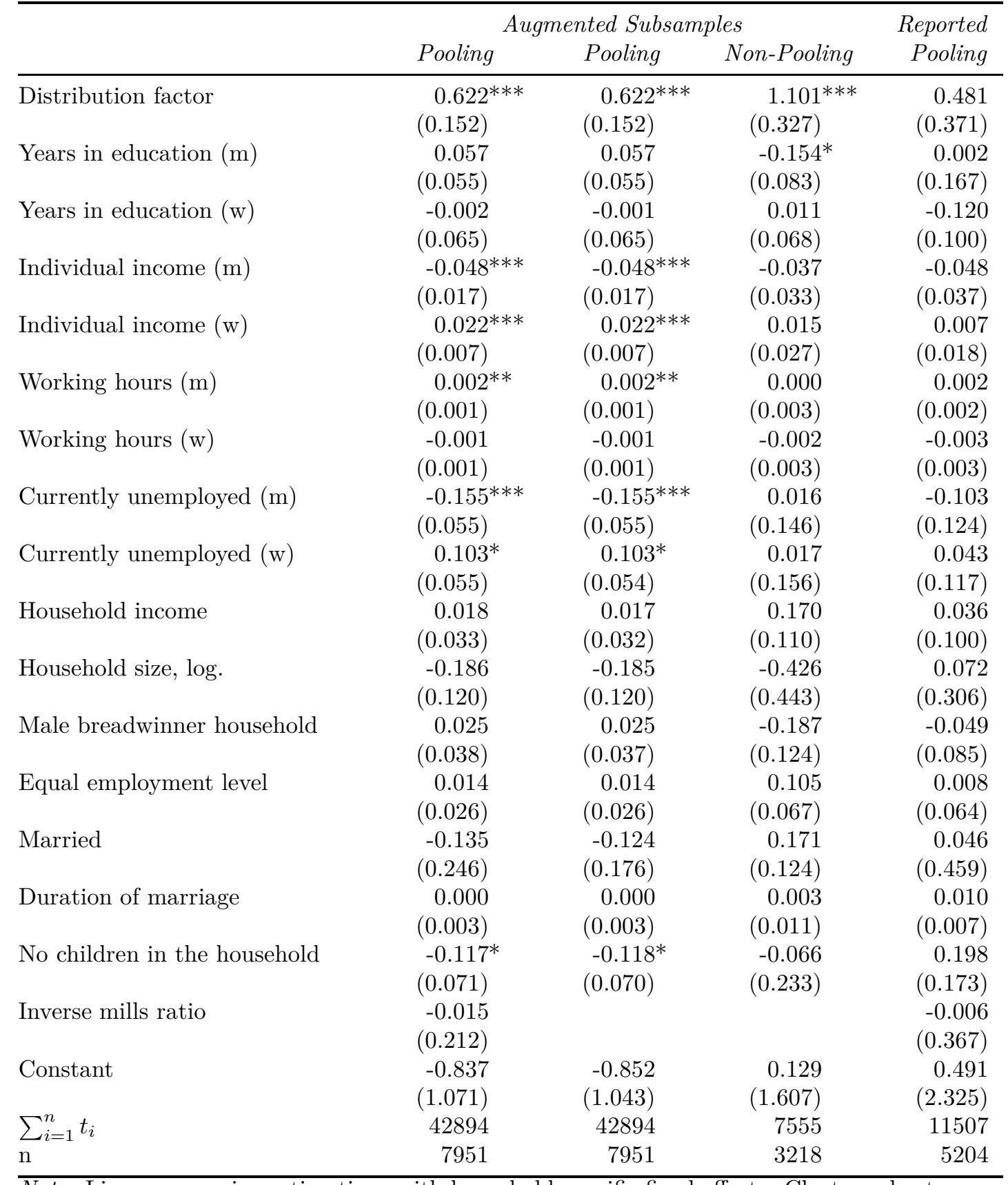

Note: Linear regression estimations with household-specific fixed effects. Cluster robust standard errors are in parentheses. Significance level: $*<0.1, * *<0.05,{ }^{*} * *<0.01$.

Source: SOEP 2000 to 2011. 
Most other covariates are insignificant, and are not intuitive to interpret. By construction, the effects of household level covariates show the difference in the influence of changes in these attributes on the man's and the woman's satisfaction. For example, the negative effect of children on the partners' difference in financial satisfaction indicates that the presence of children influences the woman's satisfaction more positively (or less negatively) than that of the man. Both reactions lead to a reduction in the satisfaction difference (which is - again - computed as the man's financial satisfaction minus the woman's financial satisfaction). The same applies to the individual characteristics that are included as controls. The effects of the partners' individual income on the satisfaction difference are perhaps the most striking estimates. The effect of the man's income in the satisfaction difference is negative while that of the woman's income is positive. This does not need to be interpreted as if increases in own income reduces individual satisfaction; it rather shows that couples do indeed pool their income. When the man's income increases and this income goes into the joint income pool, then both his and his partner's financial satisfaction will increase. The negative effect comes from the fact that the woman's financial satisfaction increases more than that of the man. An increase in the man's income augments the income pool without further contribution by the woman. Her satisfaction therefore increases to a greater extent than his satisfaction. Likewise, increases in the woman's income enhance the satisfaction difference, because the man participates in the higher joint income pool without further effort. The increase in the income pool is more costly for the partner whose individual income increased. This interpretation is supported by estimates for the subsample of couples who do not pool incomes (cf. the third model in Table 2), i.e. couples who keep entirely privatized systems of money management, couples who pool only a fraction of their incomes, and couples where only one partner manages the income pool. The effects of individual incomes on the satisfaction difference are lower and insignificant. Another expectable result for couples who do not pool their incomes is the strong and highly significant effect of the man's relative income contribution. However, the income share can not be interpreted as a distribution factor for these couples. This effect rather shows that when couples do not pool incomes the one who's income is relatively higher is more satisfied with the financial situation.

Since the prediction of income pooling was not very accurate, it could be argued that the estimated effect of the distribution factor on the satisfaction difference - which I interpret as an indication of unequal sharing between household 
partners - only comes from couples who are predicted to pool their incomes, although they do not. Due to the short number of years in which respondents were asked about their money management system and since satisfaction differences should be analyzed with fixed effects regressions, an estimation for only couples who report income pooling (exclusive of those for whom the pooling model predicts it) does not yield significant results. Although the effect of the distribution factor is not significant for this subsample with a maximum of four instead of twelve waves, it confirms the sign and size of the estimate for the subsample of couples who pool and probably pool incomes (cf. the fourth model in Table 1).

\section{Concluding Remarks}

In this study the equal sharing hypothesis was tested on a subsample of income pooling couples, since income pooling is a prerequisite for income sharing. Income sharing was identified through satisfaction differences between household partners. The equal sharing hypothesis was tested in a fixed effects regression of the satisfaction differences on individual and household characteristics and a distribution factor, i.e. the man's relative contribution to the household income. No sample selection correction was necessary, meaning that the analysis was conducted as a straightforward two-part model. The estimation results show that even couples who pool their incomes and where both partners take what they need from the pool, changes in the man's income share were statistically significantly associated with changes in satisfaction differences. Increases in the man's income share were associated with relative increases in the man's financial satisfaction, although the estimation controlled for the amount of individual income and for potential increases in the household income. This means that the relative income contribution explains the satisfaction difference, which is a clear rejection of the equal sharing hypothesis.

The rejection of the equal sharing hypothesis is in line with earlier research on the intra-household distribution of income (Elsas, 2011; Kalugina et al., 2009; Bonke and Browning, 2009, and others), consumption and well-being. My analysis goes beyond other studies that reject the equal sharing hypothesis because it takes into account the fact that only couples who pool incomes can share the household income, and because it tested for the correlation of the error terms of the sharing and the pooling equation. Unlike Bonke (2013) my study relies on 
the holistic approach to identify sharing via satisfaction answers, which directly relates sharing to the theoretically meaningful concept of utility. Finally, I use panel data that enables me to estimate a fixed effects model for the sharing equation, which cancels out couple-specific differences in the distribution of financial satisfaction as well as other couples-specific heterogeneity. The significant effect of the distribution factor therefore is unlikely to be caused by unobserved heterogeneity.

The fact that even couples who pool their incomes share according to each partner's contribution to the household income is a very strong rejection of the equal sharing hypothesis because it rules out the caveat that rejections of the equal sharing hypothesis are caused only by couples that do not pool incomes and hence can not share the household income equally. This means, according to my results, the equal sharing hypothesis is not only limited in its range because of couples who do not pool incomes but it is rejected fairly. Moreover, the analysis of pooling and sharing as two distinct steps shows that the parsimonious concept of income pooling, which prevails in standard household economics, is inadequate for understanding and describing processes within households and the outcomes of these processes. The results confirm the notion of conflicting ideals of a partnership of equals based on love and sharing and the concept of individuals who earn income as compensation for their effort as formulated by Vogler (2005). The ideal of a partnership of equals is maintained with the pooling of income, while the concept of earning income for individual effort persists when each partner takes what he or she feels to deserve out of the pool.

The practical consequence of this further rejection of the equal sharing hypothesis is that poverty and inequality statistics may draw misleading pictures of the distribution of welfare in society.

\section{References}

Alderman, H., Chiappori, P.-A., Haddad, L., Hoddinott, J., and Kanbur, R. (1995). Unitary versus collective models of the household: Is it time to shift the burden of proof? The World Bank Research Observer, 10(1):pp. 1-19.

Argyle, M. (1999). Causes and correlates of happiness. In Kahneman, D., Diener, E., and Schwarz, N., editors, Well-Being: The Foundations of Hedonic Psychology, pages 353-373. Russell Sage Foundation, New York. 
Bergstrom, T. C. (1997). A survey of theories of the family. In Rosenzweig, M. R. and Stark, O., editors, Handbook of Population and Family Economics, volume 1, Part A of Handbook in Economics, pages 21-79. Elsevier.

Bonke, J. (2013). Pooling of income and sharing of consumption within households. Review of the economics of the household, (forthcoming).

Bonke, J. and Browning, M. (2009). The distribution of well-being and income within the household. Review of Economics of the Household, 7(1):31-42.

Bourguignon, F. J., Browning, M., Chiappori, P., and Lechene, V. (1993). Intra household allocation of consumption: A model and some evidence from French data. Annales d'Économie et de Statistique, (29):137-156.

Browning, M., Bourguignon, F. J., Chiappori, P., and Lechene, V. (1994). Income and outcomes: A structural model of intrahoushold allocation. Journal of Political Economy, (102):1067-1096.

Dew, J. (2011). Financial issues and relationship outcomes among cohabiting individuals. Family Relations, 60(2):178-190.

Diener, E., Suh, E. M., Lucas, R. E., and Smith, H. L. (1999). Subjective wellbeing: Three decades of progress. Psychological Bulletin, 125(2):276-302.

Elsas, S. (2011). Behind the curtain: The within-household sharing of income. SOEP Papers, 382:1-27.

Esping-Andersen, G. (2011). The Three Worlds of Welfare Capitalism. Polity Press, reprint edition.

Ferrer-i-Carbonell, A. (2013). Happiness economics. Series, 4(1):35-60.

Ferrer-i-Carbonell, A. and Frijters, P. (2004). How important is methodology for the estimates of the determinants of happiness? The Economic Journal, 114:641-659.

Frick, J. R., Goebel, J., Schechtman, E., Wagner, G. G., and Yitzhaki, S. (2006). Using analysis of gini (ANOGI) for detecting whether two sub-samples represent the same universe. Sociological Methods $\mathscr{E}$ Research, 34(4):427-468. 
Guven, C., Senik, C., and Stichnoth, H. (2012). You can't be happier than your wife. Happiness gaps and divorce. Journal of Economic Behavior \& Organization, 82(1):110-130.

Haisken-DeNew, J. P. and Frick, J. R. (2005). DTC. Desktop companion to the German Socio-Economic Panel (SOEP). http://www.diw.de/documents/dokumentenarchiv/17/diw_01.c.38951.de /dtc.409713.pdf. (Accessed onApril 25, 2011).

Heckman, J. J. (1976). The common structure of statistical models of truncation, sample selection and limited dependent variables and a simple estimator for such models. Annals of Economic Social Measurement, 5(4):475-492.

Heimdal, K. R. and Houseknecht, S. (2003). Cohabiting and married couples' income organization: Approaches in Sweden and the United States. Journal of Marriage and Family, 65(3):525-538.

Jones, A. M. (1989). A double-hurdle model of cigarette consumption. Journal of Applied Econometrics, 4(1):23-39.

Jones, A. M. (2000). Health econometrics. In Culyer, A. J. and Newhouse, J. P., editors, Handbook of Health Economics, volume 1, Part A, pages 265344. Elsevier.

Jones, A. M. (2007). Applied Econometrics for Health Economists. A Practical Guide. Radcliffe, Oxford.

Kalugina, E., Radtchenko, N., and Sofer, C. (2009). How do spouses share their full income? Identification of the sharing rule using self-reported income. Review of Income and Wealth, 55(2):360-391.

Kenney, C. T. (2006). The power of the purse: Allocative systems and inequality in couple households. Gender and Society, 20(3):354-381.

Kulic, N. (2013). The type and duration of family unions and income sharing: The implications for women's economic well-being. Journal of Socio-Economics, $44: 7-15$.

Leung, S. F. and Yu, S. (2000). Collinearity and two-step estimation of sample selection models: Problems, origins, and remedies. Computational Economics, 15:173-199. 
Lewis, J. (2001). The End of Marriage. Edward Elgar, Cheltenham.

Lundberg, S. J., Pollak, R. A., and Wales, T. J. (1997). Do husbands and wives pool their resources? Evidence from the United Kingdom child benefit. Journal of Human Resources, 32(3):463-480.

Lyngstad, H. T., Noak, T., and Tufte, P. (2010). Pooling of economic resources: A comparison of Norwegian married and cohabiting couples. European Sociological Review, 27(5):624-635.

Madden, D. (2008). Sample selection versus two-part models revisited: The case of female smoking and drinking. Journal of Health Economics, 27(2):300-307.

McRae, S. (1993). Cohabiting Mothers. Policy Studies Institute, London.

Pahl, J. (1989). Money \& Marriage. Macmillan, Basingstoke.

Papp, L. M., Cummings, E. M., and Goeke-Morey, M. C. (2009). For richer, for poorer: Money as a topic of marital conflict in the home. Family relations, 58(1):91-103.

Phipps, S. A. and Burton, P. S. (1995). Sharing within families: Implications for the measurement of poverty among individuals in Canada. Canadian Journal of Economics, (28):177-204.

Phipps, S. A. and Burton, P. S. (1998). What's mine is yours? The influence of male and female incomes on patterns of household expenditure. Economica, 65(260):599-613.

Phipps, S. A. and Woolley, F. (2008). Control over money and the savings decisions of Canadian households. The Journal of Socio-Economics, 37(2):592-611.

Samuelson, P. A. (1956). Social indifference curves. Quarterly Journal of Economics, $70(1): 1-22$.

Schwarze, J. (2003). Using panel data on income satisfaction to estimate equivalence scale elasticity. Review of Income and Wealth, 49(3):359-372.

Singh, S. (1997). Marriage Money: The Social Shaping of Money in Marriage and Banking. Allen and Unwin, St. Leonards, Australia. 
StataCorp (2011). Longitudinal Data / Panel Data Reference Manual. Release 12. A Stata Press, College Station, Texas.

Stutzer, A. (2004). The role of income aspirations in individual happiness. Journal of Economic Behaviour and Organization, 54(1):89-109.

Thomas, D. (1993). The distribution of income and expenditure within the household. Annales d'Economie et de Statistique, (29):109-135.

Van Praag, B. and Ferrer-i-Carbonell, A. (2004). Happiness Quantified: A Satsifaction Calculus Approach. University Press, Oxford.

Van Praag, B. M. and Frijters, P. (1999). The measurement of welfare and wellbeing: The leyden approach. In Kahneman, D., Diener, E., and Schwarz, N., editors, Well-Being: The Foundations of Hedonic Psychology, pages 413-433. Russell Sage Foundation, New York.

Vogler, C. (2005). Cohabiting couples: Rethinking money in the household at the beginning of the twenty first century. The Sociological Review, 53(1):1-29.

Vogler, C. and Pahl, J. (1993). Social and economic change and the organisation of money within marriage. Employment and Society, 7(1):71-95.

Vogler, C., Wiggins, R. D., and Brockmann, M. (2006). Intimate relationships and changing patterns of money management at the beginning of the twenty first century. The Britisch Journal of Sociology, 75(3):455-482.

Wagner, G. G., Frick, J. R., and Schupp, J. (2007). The German Socio-Economic Panel Study (SOEP) - scope, evolution and enhancements. Schmollers Jahrbuch (Journal of Applied Social Science Studies), 127(1):139-169.

Winkler, A. E. (1997). Economic decision making by cohabitors: findings regarding income pooling. Applied Economics, 29(8):1079-1090.

Wooldridge, J. M. (2002). Econometric Analysis of Cross Section and Panel Data. The MIT Press, Cambridge, Massachusetts.

Wooldridge, J. M. (2009). Introductory Econometrics. South Western Cengage Learning. 


\section{A Appendix}

Table A.1: Descriptive Statistics

\begin{tabular}{|c|c|c|c|c|c|}
\hline Variable & Mean & Std. Dev. & $\begin{array}{r}\text { Within } \\
\text { Std.Dev. }\end{array}$ & Min & $\operatorname{Max}$ \\
\hline Husband's financial satisfaction & 6.45 & 2.098 & 1.154 & 0 & 10 \\
\hline Wife's financial satisfaction & 6.58 & 2.122 & 1.174 & 0 & 10 \\
\hline Husband's age & 53.99 & 14.431 & 2.691 & 21 & 99 \\
\hline Wife's age & 51.32 & 14.262 & 2.691 & 19 & 93 \\
\hline Husband's individual income & 2946.70 & 2481.896 & 1207.483 & 0 & 104300 \\
\hline Wife's individual income & 1218.04 & 1390.222 & 588.085 & 0 & 54000 \\
\hline Husband's years in education & 12.36 & 2.791 & .152 & 7 & 18 \\
\hline Wife's years in education & 11.87 & 2.587 & 164 & 7 & 18 \\
\hline Equivalent household income & 1945.47 & 1171.157 & 596.273 & 88.91 & 31754.27 \\
\hline Married & .92 & .272 & .094 & 0 & 1 \\
\hline No children & .50 & .500 & 179 & 0 & 1 \\
\hline Husband unemployed & .06 & .231 & .161 & 0 & 1 \\
\hline Wife unemployed & .05 & .223 & .157 & 0 & 1 \\
\hline Equal employment level & .48 & .500 & .289 & 0 & 1 \\
\hline Male breadwinner household & .16 & .363 & .219 & 0 & 1 \\
\hline Partners do not pool at all ${ }^{2}$ & .11 & .307 & .129 & 0 & 1 \\
\hline Income pool, held by one partner ${ }^{2}$ & .12 & .323 & .174 & 0 & 1 \\
\hline Income pooling, equal access ${ }^{2}$ & .72 & .450 & 210 & 0 & 1 \\
\hline Partial income pooling ${ }^{2}$ & .06 & .235 & .135 & 0 & 1 \\
\hline
\end{tabular}

Source: SOEP $2000-2011 . \sum_{i=1}^{n} t_{i}=49056 . n=8573 \cdot \frac{1}{n} \sum_{i=1}^{n} t_{i}=5.722$.

Notes:

${ }^{1}$ The within standard deviation describes the variation around the household-specific mean, which is: $\sqrt{\left(x_{h t}-\bar{x}_{h}+\overline{\bar{x}}_{h t}\right)^{2}}$ (StataCorp, 2011, p. 512)

$2 \quad \sum_{i=1}^{n} t_{i}=16480 . \quad n=6848 . \quad \frac{1}{n} \sum_{i=1}^{n} t_{i}=2.41$. 